\title{
A Ciência do Desenvolvimento Humano: Para Além de uma Psicologia do Desenvolvimento
}

\author{
Dessen, M. A., \& Costa Jr., Á. L. (2005). (orgs.). A ciência do desenvolvimento humano. \\ Tendências atuais e perspectivas futuras. Porto Alegre, RS: Armed. 278p.
}

Como os indivíduos entram em contato com as redes e dimensões de significados e sentidos presentes em seu contexto e em suas relações? Como esses "contatos" e inter-relações constituem o indivíduo e se tornam relevantes para o seu processo de desenvolvimento? Como o desenvolvimento humano pode ser considerado a partir de uma integração constitutiva e não excludente que leve em conta desde sistemas fisiológicos e bioquímicos até relações intersubjetivas entre indivíduos, grupos e sociedades, com seus distintos papéis, crenças, valores, rotinas, tempos e espaços?

O livro A Ciência do Desenvolvimento Humano Tendências Atuais e Perspectivas Futuras organizado pelos professores doutores Maria Auxiliadora Dessen e Áderson Luiz Costa Júnior, do Programa de Processos de Desenvolvimento Humano e Saúde do Instituto de Psicologia da Universidade de Brasília, se dedica a apontar os caminhos que a Ciência do Desenvolvimento vem trilhando na busca de tais respostas.

Os organizadores, contando com a colaboração dos alunos de pós-graduação e de seus respectivos orientadores, presenteiam os leitores com uma obra contemporânea que atualiza, de forma competente e aprofundada, o conhecimento lacunar que estudantes, professores e pesquisadores demandam sobre a Ciência do Desenvolvimento Humano. Essa é apresentada como um novo domínio científico que reúne diversas áreas do saber em torno da temática sobre desenvolvimento humano e do seu estudo em uma perspectiva integradora, com princípios e conceitos que consideram a tessitura singular e complexa que caracteriza os indivíduos e suas relações contextualizadas. Partindo dos avanços científicos das últimas décadas do século $X X$, em diferentes áreas dedicadas ao estudo do desenvolvimento humano, a
Ciência do Desenvolvimento delineia um conjunto de estudos interdisciplinares que se dedicam a entender os fenômenos relacionados ao desenvolvimento dos indivíduos, englobando as áreas social, psicológica e biocomportamental, focalizando a ontogênese dos processos evolutivos desde seus eventos genéticos constitutivos até os processos culturais.

A recém-criada Ciência do Desenvolvimento refere-se a uma orientação geral que integraliza conceitos e pesquisas sobre desenvolvimento humano, os quais enfatizam a ação recíproca e dinâmica de processos subjetivos ao longo de enquadramentos de tempo, espaços e contextos. Nessa perspectiva, os fenômenos do funcionamento individual são vistos, no curso da vida, em múltiplos níveis - dos subsistemas da genética, da neurobiologia e dos hormônios aos sistemas das famílias, redes sociais, comunidades e culturas.

Além de fornecer embasamento teórico e metodológico atualizado sobre essa nova área, o livro A Ciência do Desenvolvimento Humano - Tendências Atuais e Perspectivas Futuras apresenta as inter-relações dessa ciência com alguns campos do conhecimento que emergiram nos últimos anos, como Psicologia da Família e Psicologia da Saúde, ou com outras já tradicionais, como a Educação; e, ainda, aponta questões relevantes discutidas pela pesquisa científica internacional na sua interface com os processos de desenvolvimento humano.

A obra é organizada em cinco partes. A Parte I é dedicada a discutir, nos capítulos "A ciência do desenvolvimento humano: uma perspectiva interdisciplinar" e "Métodos de pesquisa em psicologia do desenvolvimento", tanto aspectos conceituais, teóricos, metateóricos sobre o desenvolvimento humano quanto delineamentos metodológicos de base qualitativa ou quantitativa para seu estudo, debatendo, 
ainda, as implicações éticas em pesquisa científica na área.

A Parte II apresenta contribuições teóricas e desafios metodológicos acerca do desenvolvimento humano a partir de diferentes enfoques: a base biológica (Capítulo 3, "A natureza do desenvolvimento humano: contribuições das teorias biológicas"); a abordagem bioecológica (Capítulo 4, "O modelo bioecológico de Bronfenbrenner: contribuições para o desenvolvimento humano"); a perspectiva sociocultural construtivista (Capítulo 5, "Construindo com o outro: uma perspectiva sociocultural construtivista do desenvolvimento humano").

A Parte III focaliza as contribuições da Ciência do Desenvolvimento à Psicologia da Família (Capítulo 6, "A família e suas inter-relações com o desenvolvimento humano"; Capítulo 7, "As relações maritais e sua influência nas relações parentais: implicações para o desenvolvimento da criança"; Capítulo 8, "Intervenção precoce e família: contribuições do modelo bioecológico de Bronfenbrenner").

A Parte IV mostra as interfaces entre a Ciência do Desenvolvimento e as áreas da Psicologia da Saúde (Capítulo 9, "Psicologia da saúde e desenvolvimento humano: o estudo do enfrentamento em crianças com câncer e expostas a procedimentos médicos invasivos"); e da Educação (Capítulo I0, "A ciência do desenvolvimento humano e suas interfaces com a educação"; e Capítulo II, "A relação entre criatividade e desenvolvimento: uma visão sistêmica").

A última Parte do livro A Ciência do Desenvolvimento Humano - Tendências Atuais e Perspectivas Futuras trata de duas questões contemporâneas de relevância para a compreensão dos processos de desenvolvimento humano: agressão e moralidade. O Capítulo 12, "Compreendendo a agressão na perspectiva do desenvolvimento humano", discute o conceito de agressão e suas características no ciclo de vida. $O$ Capítulo 13, "A compreensão da moralidade: contribuições teóricas da psicologia do desenvolvimento", evidencia questões relacionadas ao desenvolvimento moral humano, no que tange às abordagens teórico-filosóficas, às opções de pesquisa e de intervenção profissional.

Por fim, ainda nessa Parte $\mathrm{V}$, o último capítulo do livro, "Construindo uma ciência do desenvolvimento humano: passado, presente e futuro", enfatiza as contribuições da psicologia cultural e transcultural para o desenvolvimento humano e debate a aplicabilidade de uma "ciência do desenvolvimento".

A obra, que contou com o apoio do Instituto Max Planck para o Desenvolvimento Humano e Educação (MPI), de Berlim-Alemanha, e do Conselho Nacional de Desenvolvimento Científico e Tecnológico (CNPq), se destaca por uma linguagem simples e compreensível, sem perder o foco do aprofundamento necessário à temática em questão.

Os organizadores do livro A Ciência do Desenvolvimento Humano - Tendências Atuais e Perspectivas Futuras oferecem um guia para estudos e pesquisas sobre as intricadas interações do indivíduo e seu ambiente, à luz da orientação teórica e paradigmática da Ciência do Desenvolvimento, que permite olhar o curso de vida incorporando distinções temporais e processuais do contexto. Esta se torna, portanto, uma obra obrigatória à trajetória de formação de estudantes de graduação e de pósgraduação dos cursos de Psicologia e áreas afins, bem como uma excelente contribuição ao aprofundamento de pesquisadores e demais profissionais interessados na temática do desenvolvimento humano.

Recomenda-se, como sugerem os autores, "boa viagem" pelo mundo da Ciência do Desenvolvimento Humano!

Claisy Maria Marinho-Araujo Universidade de Brasília 